\title{
EDITORIAL
}

\section{MODERN TECHNOLOGY IN PERIPHERAL HEALTH CARE IN DEVELOPING COUNTRIES}

Instruments are essential for the practice of medicine; they are used for patient examination, to perform laboratory and imaging procedures, and to provide therapeutic interventions. Many instruments in common use today are improved versions of technology developed long ago, such as the stethoscope invented by the French physician Rene Laennec in 1816 to amplify heart sounds and make listening to the heart more convenient and acceptable.

There is no question that the application of technology has steadily improved the quality of medical practice, but it has also added to its complexity and cost. As new technology is introduced, important questions need to be asked: will using the technology result in improved diagnostic and treatment opportunities; will it allow patients to be managed more effectively? At what level of the health care system should it be applied; and at what cost? These questions become highly relevant when introducing new technology to peripheral health care systems in developing countries.

Technology appropriate for peripheral areas in developing countries should ideally be simple and rapid to perform, require no special technical expertise and sometimes no equipment, require no special storage conditions, perform to acceptable standards of quality at extremes of environmental conditions, and of course be affordable. Some laboratory tests available today meet these requirements even though they are based on sophisticated molecular principles. Rapid HIV screening tests have been widely used in hospitals and clinics in Africa for many years, replacing the original methods utilising complex equipment that was continuously failing in peripheral areas. On the other hand, malaria dipstick tests have not proved superior to the traditional wellstained, well examined blood slide for accuracy, low cost and flexibility: the ability to confirm malaria parasite species and provide a quantitative result, so vital for clinical management(1). However, in sites without a microscope and trained personnel, malaria dipsticks may soon find an important role in the diagnosis of patients with fever. With increasing resistance to commonly used antimalarial drugs and the need to change to more costly combination therapy, cost-benefit is now a subject for discussion and the more accurate diagnosis of malaria, as opposed to the blind treatment of all patients with fever, has become an important consideration in rural health programmes(2).

Most medical procedures do require the use of equipment, and Ogembo-Kachieng' a and Ogara in this issue of the Journal address the problems of poor selection and maintenance of medical equipment in Africa, citing information gathered from equipment maintenance specialists in Kenya and South Africa(3). Choosing medical equipment should be linked to issues of utilisation and maintenance, but this is not always done. Pressures are placed on Ministries of Health by international agencies and donors to introduce technology that is neither appropriate nor affordable. This practice is contrary to the principle of the Alma-Ata Declaration on Primary Health Care, which states that any choice of western medical technology should conform to cultural, social, economic and epidemiological conditions(4). Ogembo-Kachieng'a and Ogara confirm that most "high-tech" equipment donated to hospitals ends up in equipment storerooms and benefits mainly the donor. Reasons include lack of consumables and spare parts, lack of user and service manuals, and problems with the power supply. The authors have identified the major issues behind the poor functional state of medical equipment, from central procurement practices to utilisation at peripheral sites. Among these are central tender boards lacking experts on equipment operation and maintenance, proper warranties and service contracts not put in place, hospital engineering departments not consulted on issues of equipment procurement, and inadequate budgets for equipment maintenance.

The authors also point out that many equipment failures are user-related. Users of equipment are rarely trained in its operation, care and maintenance, and user and service manuals are frequently not available or are provided in a language the users do not understand. In a survey of the laboratory services system of mainland Tanzania conducted in 1989 (5), workshop repair staff estimated that $10-40 \%$ of faults were due to mishandling by laboratory staff. Faults included running distillation units dry, dropping equipment, leaving electrical equipment on continuously and sending faulty equipment to local repair men. Frequent reasons for sending equipment for repair included blown bulbs and rectifiers damaged by power fluctuations, distillation units developing deposits from hard or muddy water, and microscope lenses growing fungus in humid areas. The reasons given by workshop maintenance engineers for being unable to repair equipment included lack of spare parts, old models for which spare parts were no longer available, and electrical circuits that had been tampered with.

The availability of alternative power sources now makes it possible to provide modern technology to peripheral areas. No health facility, however remote, need be without a power supply. African countries have led the way in the use of solar-powered refrigerators for the vaccine cold chain. Battery banks recharged by solar (photovoltaic) cells or generators are also widely used for operating laboratory equipment, and for emergency lighting for operating theatres and delivery rooms. Inverters may be used for equipment operating on mains voltage AC power; some equipment such as microscopes, centrifuges and colorimeters are ready manufactured to use DC voltage. 
However, the availability of different power sources and procurement of equipment from countries with different mains voltage AC power can lead to problems. I once visited a laboratory that was operating equipment on four different power sources: 12 and 24 volts DC; and 120 and 240 volts AC, which could seriously compromise safety. However, photovoltaic systems play a significant role in meeting the energy needs of peripheral health facilities and can function well as long as the system is properly installed by expert technicians and the users of the equipment are trained in operating and maintaining the system. The disadvantages include a large initial financial outlay, but the advantages are greater reliability than with generators, and low running and maintenance costs.

The problems of maintaining medical equipment in a functional state is a continuous challenge to health care systems in developing countries. In developed countries, maintaining health care equipment is usually the responsibility of the hospital medical engineering department. In developing countries, this system also appears to work well in major centres close to towns and cities. Equipment agents provide service contracts and make onsite visits, even providing standby equipment while repairs are carried out. In outlying areas, the system of posting maintenance engineers to peripheral hospitals has proved disappointing. The engineers are not familiar with the wide range of equipment provided and are constantly compromised by lack of spare parts. During a feasibility study of primary health care laboratories carried out by AMREF in Kenya between 1992 and 1994 (6), most defective equipment could not be repaired by the district medical engineers and had to be referred centrally for repair.

Equipment maintenance starts with training users in correct operation, basic care and maintenance procedures. All health facilities need to establish reasonable equipment maintenance budgets. Small items of equipment should be transported from peripheral areas to central or regional sites, and qualified engineers need to make on-site visits to repair larger items. Ogembo-Kachieng'a and Ogara(3) suggest identifying specialised organisations to undertake this role. This system would seem to be the most effective for maintaining equipment in areas of Africa with limited engineering expertise and poor transport and communication systems.

Effective use and maintenance of medical equipment in peripheral areas begins with strong central planning. Standardising procedures and selecting the equipment needed to carry them out is a vital role that Ministries of Health in developing countries should take up. For every level of health facility, an inventory of medical procedures should be drawn up, taking into consideration power and water supplies, medical and technical expertise, supply systems and access to equipment maintenance services.

Stringent criteria for equipment selection need to be established as policy guidelines; these guidelines should apply to donations as equally as to equipment procured by health administrations. Will this technology address the medical problems capable of being managed at that level of health facility? can it be operated by the technical staff usually found at that level? Does it have an acceptable degree of accuracy and reliability? Is the technology durable and robust; will it function well in conditions of high and low temperature, humidity or dust? Does the power requirement conform to the national power supply? Is it safe to operate, and are there suitable protection devices? Is the technology subject to routine quality control procedures? Can the equipment be easily assembled and disassembled for cleaning, repair and decontamination? What is the cost of its purchase, operation, maintenance and repair? Will the patients - the users of the servicesbe able to contribute to these costs to ensure sustainability?(7).

The role of Ministries of Health is to guide users in selecting technology by standardising services at every level of health services delivery, by evaluating appropriate techniques and equipment, by making use of technical experts in the equipment procurement process, and by training equipment users. Clear specifications for major items of equipment will limit the types of equipment in use, which will make it much easier to ensure that consumables and spare parts are available, users are familiar with the operation of equipment, and maintenance engineers can repair them. A streamlined system of equipment supply and maintenance will ultimately reduce cost. In selecting medical equipment, capital cost is not the most important issue; good quality equipment with a higher purchasing price may eventually cost less. In peripheral health facilities simple, well-tried technologies are often still the best solution for providing a combination of acceptable performance, familiarity and dependability.

\author{
J. Y. Carter, MBBS, FRCP (C) \\ Head, Clinical Services \\ African Medical and Research Foundation \\ P.O. Box 30125-00100 GPO, Nairobi, Kenya
}

\section{REFERENCES}

1. Lema, O.E., Carter, J.Y., Nagelkerke, N., and Mukunza, H.K. Comparison of five methods of malaria diagnosis in the outpatient setting. Amer. J. Trop. Med. Hyg. 1999; 60:177-182.

2. Rimon, M.M., Kheng, S., Hoyer, S., Thach, V. Ly, S, Permin, A.E. and Pieche, S. Malaria dipsticks beneficial for IMCI in Cambodia. Trop. Med. Int. Health 2003; 8:536-543.

3. Ogembo-Kachieng'a, M. and Ogara, W.O. Strategic management of technology in the public health sector in Kenya and South Africa: professional view from health equipment experts. East Afr. Med. J. 2004; 81.

4. Banerji, D. Reflections on the twenty-fifth anniversary of the Alma-Ata Declaration. Int. J. Health Serv. 2003; 33:813-818.

5. Carter, J.Y., Lema, O.E. and Rees, P.H. Health laboratory services system of mainland Tanzania. an evaluation. Nairobi: Ministry of Health, AMREF, Swiss Development Cooperation, 1989.

6. Essential Laboratory Programme Pilot Study. Nairobi: Ministry of Health, Kenya/African Medical and Research Foundation. 1992-1994.

7. Johns, L.J. and EI-Nageh, M.M. Selection of basic laboratory equipment for laboratories with limited resources. Geneva: World Health Organization. 2000. 